\title{
Computed Tomography Evaluation of Blunt Abdominal Injury
}

\author{
Sholy K Vareed ${ }^{\oplus 1}$, Don Paul Mathew ${ }^{\circledR 2}$, Justine Antony ${ }^{\circledR 3}$ \\ ${ }^{1}$ Associate Professor, Department of Radiodiagnosis, SNIMS, Chalakka, Ernakulam, India, ${ }^{2}$ Assistant Professor, Department of Radiodiagnosis, SNIMS, Chalakka, \\ Ernakulam, India, ${ }^{3}$ Senior Resident, Department of Radiodiagnosis, SNIMS, Chalakka, Ernakulam, India.
}

\section{Abstract}

Background: Unlike penetrating abdominal trauma, where management is largely determined clinically, the diagnosis of blunt abdominal injury by clinical examination is unreliable, particularly in patients with a decreased level of consciousness. Plain abdominal radiography has limited role in the assessment of blunt abdominal trauma, although some authorities continue to advocate its use. CT scan's main advantage is the ability to detect arterial contrast extravasation, uncontained or as a pseudoaneurysm, which predicts the need for surgery or angioembolisation. The aim is to study computed tomography evaluation of blunt abdominal injury. Subjects and Methods: The present study was conducted in the Department of Radiology of the medical institution. For the study, we used abdomen CT scan reports of 100 patients with BAT, who were stable enough to undergo radiological investigation. The patients included 66 males and 34 females. All CT scans were obtained with a 16 slice MDCT Scanner (Siemens). All patients received intravenous bolus of iodinated contrast agents. Individual organ injuries were graded according to the American Association for the Surgery of Trauma (AAST - OIS) injury scoring scale. The overall imaging findings were analysed for their role in guiding the therapeutic options, whether conservative or surgical. Results: Total number of patients included in the study was 100 . The mean age of patients was 41.97 years. Number of male patients was 66 and number of female patients was 34 . For the mode of injury, other miscellaneous causes were most common in out study group followed by road traffic accidents. It was observed that OIS grade II patients were 19, OIS grade III patients were 29, OIS grade IV patients were 12 and OIS grade V patients were 10 . The highest proportion of conservatively managed patients were seen in OIS grade II patients. Conclusion: Within the limitations of the present study, it can be concluded that CT scan for blunt abdominal injury is a reliable and accurate method for diagnosis. It has all the qualities to make it a gold standard for initial investigation of choice for blunt abdominal injury patients.

Keywords: Blunt Abdominal Injury, Abdominal Trauma, CT scan, Organ Injury

Corresponding Author: Don Paul Mathew, Assistant Professor, Department of Radiodiagnosis, SNIMS, Chalakka, Ernakulam, India. E-mail: donpaulm@yahoo.com

Received: 25 September 2020

Revised: 08 November 2020

Published: 30 December 2020

\section{Introduction}

Unlike penetrating abdominal trauma, where management is largely determined clinically, the diagnosis of blunt abdominal injury by clinical examination is unreliable, particularly in patients with a decreased level of consciousness. ${ }^{[1,2]}$ Confirmation of the presence or absence of injury therefore relies largely on the use of diagnostic adjuncts. Late diagnosis and missed injuries are associated with poor outcome. A large prospective observational study of patients with blunt polytrauma but no clinical signs of injury-which found radiological evidence of abdominal injury in almost $10 \%$ of patients - and a recent consensus guideline suggest that the threshold for investigation of blunt abdominal trauma should be low. ${ }^{[3,4]}$ Plain abdominal radiography has limited role in the assessment of blunt abdominal trauma, although some authorities continue to advocate its use. Plain abdominal radiography does not visualise abdominal viscera or detect free fluid, so it cannot provide direct evidence of organ injury or indirect evidence of haemorrhage. ${ }^{[5]} \mathrm{CT}$ scan's main advantage is the ability to detect arterial contrast extravasation, uncontained or as a pseudoaneurysm, which predicts the need for surgery or angioembolisation. Computed tomography can be used to evaluate retroperitoneal injury, whereas DPL and ultrasound are less sensitive. Computed tomography is also the modality of choice for diagnosing injuries to the diaphragm, which may result in major morbidity and mortality if undetected and may not present until many years after the event. ${ }^{[6]}$ Hence, the present study was conducted to study computed tomography evaluation of blunt abdominal injury. 


\section{Subjects and Methods}

The present study was conducted in the Department of Radiology of the medical institution. The ethical clearance for the study was approved from the ethical committee of the hospital. For the study, we used abdomen CT scan reports of 100 patients with BAT, who were stable enough to undergo radiological investigation. The patients included 66 males and 34 females. The age range was $14-72$ years. Diagnostic peritoneal tapping was not performed in any of them. Patients with a normal CT scan and patients who either did not require admission, or who were discharged after a short, uneventful (max. 3 day) observation period without any further investigation, were excluded from the study. All CT scans were obtained with a 16 slice MDCT Scanner (Siemens). All patients received intravenous bolus of iodinated contrast agents. Following completion of the examination, the CT images were immediately reviewed by two specialist radiologists. Individual organ injuries were graded according to the American Association for the Surgery of Trauma (AAST OIS) injury scoring scale. The OIS classification scheme is fundamentally an anatomic description, scaled from 1 to 5 , representing the least to the most severe injury, ie. from simple organic contusion to avascularisation of one organ. CT findings were compared with operative findings, and with the clinical outcome and follow-up. The results were analysed with respect to hemoperitoneum quantification and OIS grades. The overall imaging findings were analysed for their role in guiding the therapeutic options, whether conservative or surgical.

\section{Results}

[Table 1] shows demographic variables of the participants. Total number of patients included in the study was 100 . The mean age of patients was 41.97 years. Number of male patients was 66 and number of female patients was 34 . For the mode of injury, other miscellaneous causes were most common in out study group followed by road traffic accidents. [Figure $1 \&$ Table 2] shows CT-OIS grading and management in 70 patients with solid organ injuries. It was observed that OIS grade II patients were 19, OIS grade III patients were 29, OIS grade IV patients were 12 and OIS grade V patients were 10. The highest proportion of conservatively managed patients were seen in OIS grade II patients. However, highest proportion of operated patients was seen in OIS grade $\mathrm{V}$ patients. [Figure 2]

\section{Discussion}

In the present study, records of 100 patients were studied. 66 patients were males and 34 were females. The mean age was 41.97 years. The most common cause of blunt trauma injury

\begin{tabular}{|ll|}
\hline \multicolumn{2}{|c|}{ Table 1: Demographic variables of the participants } \\
\hline Demographic variables & Values \\
\hline Total number of patients & 100 \\
\hline Mean age (years) & 41.97 \\
\hline Number of males & 66 \\
\hline Number of females & 34 \\
\hline Road traffic accident & 32 \\
\hline Fall from height & 29 \\
\hline Other miscellaneous causes & 39 \\
\hline
\end{tabular}
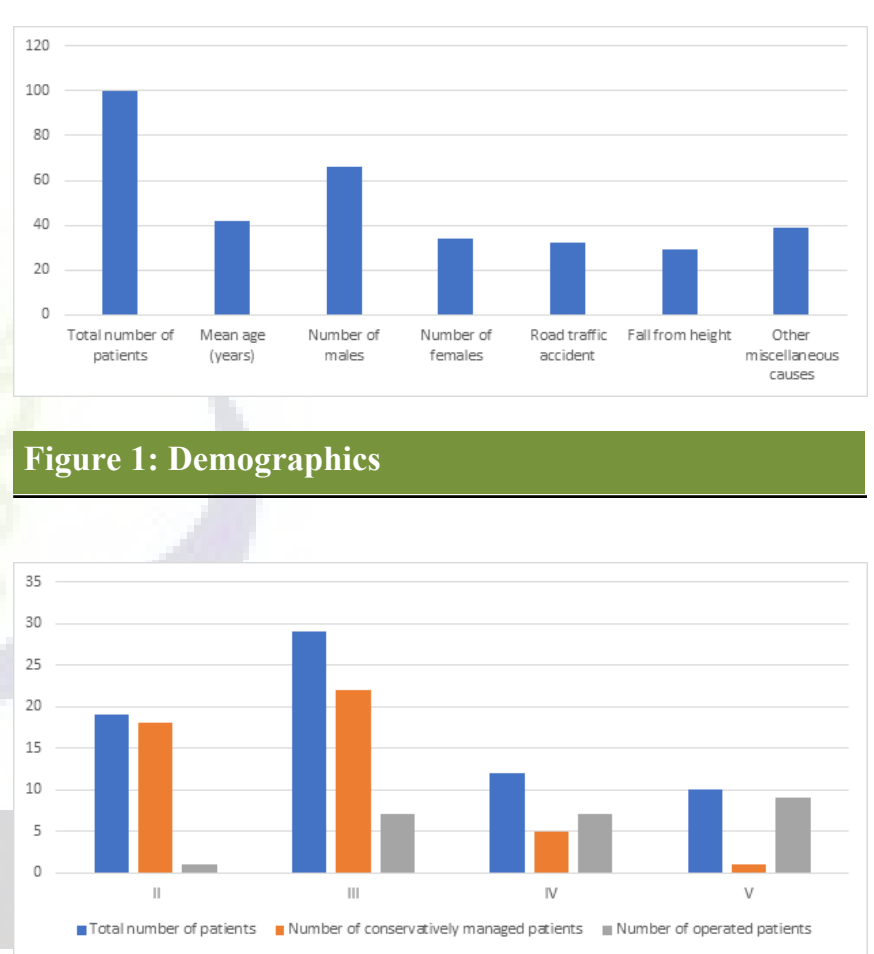

Figure 2: CT-OIS grading and management in patients with solid organ injuries

in our study was miscellaneous injury followed by road traffic accidents. Bell $\mathrm{C}$ et al studied two procedures, diagnostic peritoneal lavage (DPL) and computed tomography (CT scan) to evaluate patients with possible intraabdominal injuries after blunt trauma. There are advantages and disadvantages of both procedures, however, present evidence suggests that the clinician should not rely on the results of the CT scan. They concluded that the DPL, on the other hand is a sensitive and specific modality in evaluating the patient with blunt abdominal trauma. ${ }^{[7]}$ Hamidi MIet al, ${ }^{[8]}$ determined the utility of the computed tomography (CT) scan in blunt abdominal trauma and to compare it with operative findings or clinical outcomes. A retrospective analysis based on existing, 


\begin{tabular}{|c|c|c|c|}
\hline OIS grade & Total number of patients & $\begin{array}{l}\text { Number of conserva- } \\
\text { tively managed patients }\end{array}$ & $\begin{array}{l}\text { Number of operated } \\
\text { patients }\end{array}$ \\
\hline II & 19 & 18 & 1 \\
\hline III & 29 & 22 & 7 \\
\hline IV & 12 & 5 & 7 \\
\hline V & 10 & 1 & 9 \\
\hline
\end{tabular}

diagnostic CT scan reports taken during a 5 year period from 245 consecutive patients with blunt abdominal trauma. Percentages and types of trauma identified were based on CT scan findings. Of the total of 245 patients, $113(46 \%)$ underwent surgery. One hundred and thirty two (54\%) patients were conservatively managed. In our study, $65.71 \%$ patients were conservatively managed and $34.28 \%$ patients underwent surgery.

Hamidi Ml et al, ${ }^{[8]}$ graded organ injuries using the OIS (Organ Injury Scale) guidelines, similar to our study. They concluded that $\mathrm{CT}$ was reliable in the evaluation of blunt abdominal trauma in a selected group of patients, with overall sensitivity of $97 \%$ and specificity of about $95 \%$. Positive predictive value $82 \%$ and negative predictive value $100 \%$. ${ }^{[8]}$

Becker CD et al studied the CT scans of adult patients with proved blunt splenic injuries to determine if the findings accurately reflect the extent of the injury. The CT scans of 45 patients with blunt splenic injuries were analyzed retrospectively, and the CT findings were correlated with the need for surgery. According to the CT scale (I-V), 25 patients had injuries of grade I or II; 20 patients were successfully treated conservatively, whereas five patients needed delayed surgery. Nineteen patients had injuries of grade III, IV, or V; eight patients underwent early laparotomy, and 11 patients were successfully treated conservatively. CT findings were false-negative in one patient who underwent early surgery for diaphragmatic rupture. A comparison of the CT findings with the intraoperative findings according to the $\mathrm{CT}$ scale (I-V) revealed identical parenchymal injury grades in four cases, whereas the injuries were underestimated on CT scans in four patients and overestimated on CT scans in six patients. The CT-based score was applied to 41 patients; four patients who had peritoneal lavage before CT were excluded. Twelve patients had scores below $2.5 ; 10$ patients were successfully treated conservatively, and two patients needed delayed surgery. Twenty-nine patients had scores of 2.5 or higher; six patients underwent early laparotomy, 20 patients were successfully treated conservatively, and three patients needed delayed surgery. Patients who required delayed surgery had a mean score of $3.0(\mathrm{SD},+/-1.0)$, which was similar to those who did not require surgery. Their results showed that $\mathrm{CT}$ findings cannot be used to determine reliably which patients require surgery and which patients can be treated conservatively. ${ }^{[9]}$ Mehta $\mathrm{N}$ et al evaluated 71 cases of BAT with stress on early diagnosis and management, increase use of non operative management, and time of presentation of patients. A retrospective analysis of 71 patients of BAT who were admitted in Kempegowda Institute of Medical Sciences hospital (KIMS, Bangalore, India) within a span of 18 months was done. Demographic data, mechanism of trauma, management and outcomes were studied. Motor vehicle accident $(53 \%)$ was the most common mechanism of injury. Spleen (53\%) was the commonest organ injured and the most common surgery performed was splenectomy (30\%). Most common extra abdominal injury was rib fracture in $20 \%$. Mortality rate was $4 \%$. Wound sepsis $(13 \%)$ was the commonest complication. Initial resuscitation measures, thorough clinical examination and correct diagnosis forms the most vital part of management. $70 \%$ of splenic, liver and renal injuries can be managed conservatively whereas hollow organs need laparotomy in most of the cases. ${ }^{[10]}$

Meyer DM et al determined the sensitivity, specificity, and accuracy of CT in pediatric patients with blunt trauma. Sixty children sustaining blunt abdominal trauma were included in the study. CT scans with both oral and IV contrast were performed before open lavage, and positive results were confirmed by operation in 18 patients. CT had a sensitivity of $67 \%$, however, only $60 \%$ of the actual organ injuries were identified by the scan. In contrast, DPL has a sensitivity of $94 \%$. Both studies were equally specific (100\%). DPL was also more accurate, $98 \%$ as compared with $89 \%$ for CT. They concluded that the abdominal CT scan is useful in evaluating children with blunt abdominal trauma, a number of significant injuries were missed. ${ }^{[11]}$

\section{Conclusion:}

Within the limitations of the present study, it can be concluded that $\mathrm{CT}$ scan for blunt abdominal injury is a reliable and accurate method for diagnosis. It has all the qualities to make it a gold standard for initial investigation of choice for blunt abdominal injury patients. 


\section{References}

1. Weledji P. Perspectives on the Management of Abdominal Trauma. J Univer Surg. 2018;6(2):17.

2. Myers J. Focused assessment with sonography for trauma (FAST): the truth about ultrasound in blunt trauma. J Trauma. 2007;62:28. Available from: https://doi.org/10.1097/ ta.0b013e3180654052.

3. Hoff WS, Holevar M, Nagy KK, Patterson L, Young JS, Arrillaga A, et al. Eastern Association for the Surgery of Trauma. Practice management guidelines for the evaluation of blunt abdominal trauma: the EAST practice management guidelines work group. J Trauma. 2002;53:602-617. Available from: https://doi.org/10.1097/00005373-200209000-00038.

4. Salim A, Sangthong B, Martin M, Brown C, Plurad D, Demetriades D. Whole body imaging in blunt multisystem trauma patients without obvious signs of injury. Arch Surg. 2006;141(5):468-475. Available from: https://doi.org/10. 1001/archsurg.141.5.468.

5. Jansen JO, Yule SR, Loudon MA. Investigation of blunt abdominal trauma. BMJ. 2008;336(7650):938-942. Available from: https://dx.doi.org/10.1136/bmj.39534.686192.80.

6. Brody JM, Leighton DB, Murphy BL, Abbott GF, Vaccaro JP, Jagminas L, et al. CT of Blunt Trauma Bowel and Mesenteric Injury: Typical Findings and Pitfalls in Diagnosis. Radio Graphics. 2000;20(6):1525-1536. Available from: https://dx. doi.org/10.1148/radiographics.20.6.g00nv021525.

7. Bell C, Coleridge ST. A comparison of diagnostic peritoneal lavage and computed tomography (CT scan) in evaluation of the hemodynamically stable patient with blunt abdominal trauma. J Emerg Med. 1992;10(3):275-280. Available from: https: //dx.doi.org/10.1016/0736-4679(92)90332-n.
8. Hamidi MI, Aldaoud KM, Qtaish I. The role of computed tomography in blunt abdominal trauma. Sultan Qaboos Univ Med J. 2007;7(1):41-46.

9. Becker CD, Spring P, Glättli A, Schweizer W. Blunt splenic trauma in adults: can CT findings be used to determine the need for surgery? Am J Roentgenol. 1994;162(2):343-347. Available from: https://dx.doi.org/10.2214/ajr.162.2.8310923.

10. Mehta N, Babu S, Venugopal K. An experience with blunt abdominal trauma: evaluation, management and outcome. Clin Pract. 2014;4(2):599-599. Available from: https://dx.doi.org/ 10.4081/cp.2014.599.

11. Meyer DM, Thal ER, Coln D, Weigelt JA. Computed Tomography in the Evaluation of Children with Blunt Abdominal Trauma. Annals of Surg. 1993;217(3):272-276. Available from: https://dx.doi.org/10.1097/00000658-19930300000009 .

Copyright: (C) the author(s), 2020. It is an open-access article distributed under the terms of the Creative Commons Attribution License (CC BY 4.0), which permits authors to retain ownership of the copyright for their content, and allow anyone to download, reuse, reprint, modify, distribute and/or copy the content as long as the original authors and source are cited.

How to cite this article: Vareed SK, Mathew DP, Antony J. Computed Tomography Evaluation of Blunt Abdominal Injury. Asian J. Med. Radiol. Res. 2020;8(2):57-60.

DOI: dx.doi.org/10.47009/ajmrr.2020.8.2.9

Source of Support: Nil, Conflict of Interest: None declared.

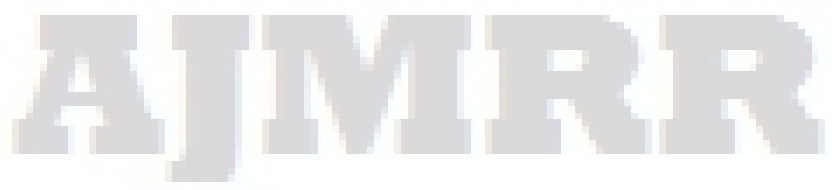

